\title{
ERRATUM
}

\section{Erratum to: Micropropagation of Three Commercial Cultivars of Hazelnut (Corylus avellana L.)}

\author{
Neda Mardani ${ }^{1}$ - Ali Khadivi ${ }^{1}$ Ali Vatanpour-Azghandi ${ }^{2}$ \\ Published online: 6 December 2019 \\ ○ Springer-Verlag GmbH Deutschland, ein Teil von Springer Nature 2019
}

\section{Erratum to:}

\section{Gesunde Pflanzen 2019}

https://doi.org/10.1007/s10343-019-00481-7

Unfortunately the authors have forgotten to add the "Acknowledgments" section to this paper. The section should be as follows:

Acknowledgements The current work was supported by the Agricultural Biotechnology Research Institute of Iran (ABRII) as a part of Project no 2-05-05-88026. The authors would like to thank ABRII for its supporting and providing in vitro plant materials.

The online version of the original article can be found under https://doi.org/10.1007/s10343-019-00481-7.

$\triangle$ Ali Khadivi

a-khadivi@araku.ac.ir

1 Department of Horticultural Sciences, Faculty of Agriculture and Natural Resources, Arak University, 38156-8-8349, Arak, Iran

2 Agriculture Biotechnology Research Institute of Iran (ABRII), 31535-1897, Karaj, Iran 